\title{
La comarca de Vuelta Abajo, isla de Cuba, en 1755. Recuento de un obispo ilustrado
}

A Don Luis Mena, párroco y amigo

Pablo J. Hernández González

Universidad de La Habana. Cuba

Con una breve presentación en la que se apuntan unas notas biográficas sobre el obispo de La Habana Pedro Agustín Morel de Santa Cruz, se presenta un expediente inédito depositado en el Archivo General de Indias de Sevilla, sobre la visita que dicho obispo realizó a la comarca de Vuelta Abajo —en la isla de Cuba- en la década de 1750. En su texto, como es habitual en este tipo de documentos, se señalan notas esenciales para el conocimiento de la región en aquella época. En sus páginas aparecen desde descripciones geográficas -más o menos acertadas - a la explicación del estado de las iglesias de la zona; pero, sobre todo, y como casi todas las visitas pastorales, nos ofrece interesantes datos sobre la población y sus medios de vida.

En la toponimia al uso del siglo XVIII, Vuelta Abajo calificaba una dilatada región al Oeste del meridiano de La Habana ' ${ }^{1}$ y que en el pausado discurrir de las dos primeras centurias de la colonización apenas había despertado más interés que el de la geofagia ganadera trashumante y sus rivales los cultivadores de tabaco en perenne litigio por el dominio del espacio aprovechable. Ciertamente, en los años terminales del XVII, si bien con un monto poblacional aún menguado, ciertas localidades relacionadas con la explotación agropecuaria habían conseguido relativa importancia, como para despertar el interés de las instituciones del poder - tanto en su autoridad temporal como en la espiritual-, incitándolas a definir su relativamente escasa presencia en las regiones más occidentales de

I Acerca de las definiciones geográficas, véase de José María de la Torre, su Compendio de Geografía Física, Política, Estadística y Comparada de la Isla de Cuba, La Habana, 1854 y también de Jacobo de la Pezuela: Diccionario geográfico, estadístico, histórico de la Isla de Cuba, Madrid, 1863-1866. 
la Isla y donde no pocos vecinos capitalinos disfrutaban inversiones desde mucho. ${ }^{2}$

El interés eclesiástico en la región, y con esto un mejor conocimiento del territorio y sus gentes, data de la segunda mitad del siglo XVII, cuando el entonces obispo Juan García de Palacios, referíase al estado del culto en el interior de la Isla, considerándolo lamentable al quedar las personas que residían en las haciendas, privadas del ritual por la extrema lejanía de la capital. Particularizando en el caso que nos interesa, acotaba que del lado de Sotavento de la Isla se extendía una comarca de "...mas de sesenta [leguas] sin haver en tantas leguas pueblo alguno, en que asista ministro...”. Proyectaba, y de ahí su consulta, colocar varios ministros seculares o regulares "...a distancia proporcionada en algunas hermitas que ay interin se fabrican Yglesias...", y así intentaba conseguir que los hacendados contribuyeran a su mantenimiento, además de sugerir a la Corona se le facilitaran fondos para tal fin, extrayéndolos de las plazas vacantes de la guarnición, como era práctica con los capellanes castrenses. ${ }^{3}$ Podían paliar la situación - estimaba-, destacando en la Vuelta Abajo dos o tres ministros, al considerar la existencia allí de un centenar de haciendas de ganado mayor y menor, labranzas de tabaco y pesquerías, que sostenían cerca de 800 personas y escribía “(...) Cada ministro en el lugar o parte mas proporcionada para la mejor administración...”, mientras que las jurisdicciones eclesiásticas comprenderían "...diez o doce leguas de contorno para que assí puedan acudir á las necesidades que en el discurso del año se ofrecieren...". ${ }^{4}$

Al siguiente año, 1680, el prelado dispuso que una comisión visitase los parajes propuestos para edificar ermitas e informase lo pertinente. Advertía en su despacho, que los encargados de la co-

2 No es pródiga la historiografía particular de la Vuelta Abajo; probablemente la más generalizadora, a la vez que consultada, sea la obra de Emeterio Santovenia: Pinar del Río, México, D. F., 1956.

3 Archivo General de Indias (en adelante AGI), Santo Domingo, 106. El obispo Juan García de Palacios a S. M., La Habana, 15 de mayo de 1679.

4 Ibídem. El obispo de Cuba a S. M., La Habana, 20 de mayo de 1679. 
misión debían ser sujetos "...que tienen conocimiento de la Ysla y de dichos Paraxes y de las haciendas y poblaciones que en ellos ay y los quales sean más á propósito para poner en ellos a dhos ministros que estén con alguna Seguridad de los enemigos Piratas que infestan esta Costa, y Promptos a la mejor administracion de los Santos Sacramentos...". 5

Sucesor de García de Palacios (1687), Diego Evelino de Compostela prosiguió el interés de aquél en el fomento de los "curatos del campo" a lo largo de la Isla, especialmente en la Vuelta Abajo o Sotavento de La Habana, que comenzaba a cobrar interés conforme sus recursos y población ganaban en consistencia. Al resumir su primer bienio en el Obispado cubano (1689) destacaba, escribiendo a la Corte, que prácticamente desde el inicio cursó avisos para que se hiciere exacta relación de los lugares a Sotavento y Barlovento de La Habana “...y el número de feligreses españoles e Yndios que ay en este Obispado...”. En lo que a Sotavento concierne, y en el apartado relativo a ingenios, estancias y hatos, enumeraba los de Santo Xpto y Consolación, el primero habitado por 49 familias que sumaban 150 personas, el segundo con 39, llegando a 260 almas. $^{6}$ Un lustro después, y cumplimentando los acuerdos del Sínodo del Obispado insular en materia de límites y términos jurisdiccionales de las diversas parroquias, y ante la enorme confusión que existía al respecto, dictaminó que "...para mayor y mas promta administración de los sacramentos..." y puesto que la parroquial mayor de la Habana "...tampoco tiene terminos ni limites fixos [se le señalan] por terminos y linderos todas las leguas que ay pasadas las que te-

5 Ibídem. El obispo de Cuba a S. M., La Habana, 6 de septiembre de 1680.

6 Ibídem. "Matrícula de las familias y Personas que ay en las cinco ciudades y siete villas de que se compone su Diocesi y ajustada por los Padrones que los Curas de las Higlesias Parroquiales an remitido pertenecientes a este presente año de mil siscientos y ochenta y nueve"; Idem. El obispo de Cuba a S. M., La Habana, 28 de septiembre de 1689. Según un padrón de los curatos de campo preparado por el obispo Compostela en 1696, de la Vuelta Abajo se relacionaban cuatro curatos: San Hilarión de Guanajay, con 148 habitantes; Santa Cruz, con 161; Nuestra Señora de Consolación, con 224, y San Ildefonso de Guane, con 169. Entre todos comprendían 39 hatos y 109 corrales, en un territorio de alrededor de 70 leguas de extensión. (Idem. Además, véase a Marrero, Leví: Cuba: Economía y Sociedad, Madrid, 1976, tomo 5, capítulo 12, 88-92). 
nemos señaladas á la parroquial de la Villa de Guanabacoa hasta los terminos en que estubieren en possession las Parroquiales de la Ciud. de la Trinidad, Sancti Spiritus, y San Jua. de los Remedios, por la parte que llaman Costa del Norte, y las que ay desta Ciudad por la parte del Sur hasta Cabo de Corrientes, para que todas las personas libres o esclabos que vivieren y murieren dentro de dichas leguas assí en la parte del sur como en la del Norte en Corrales, Hatos, Vegas, estancias e ingenios los Curas de dhas Iglesias Parroquiales de San Christobal, y el Spiritu Sto. les administren los Santos Sacramentos, y las reconozcan por sus Ovejas, y feligreses, para dar cuenta a nro. Sr. dellas y ellos reconozcan a dhos curas por sus proprios Parrocos, y les acudan con los derechos Parroquiales, obenciones, Primicias y parte de Diezmos que su Magd. les tiene aplicados...". 7

No es ocioso rememorar que los datos precedentes se sustentan en un reconocimiento espacial remontado a la última década del siglo XVII y fue resultado de la gestión del obispo Compostela, quien (no tanto por sus limitados recorridos personales en virtud de su salud como por el empleo frecuente de delegados particulares) acopió un conocimiento actualizado y fidedigno de la Vuelta Abajo, en especial su vertiente meridional, por entonces la más accesible a las rudimentarias condiciones de penetración caminera, y donde no casualmente se concentraba el mayor número de haciendas y fincas. ${ }^{8}$ Débese a este prelado durante el desempeño de sus funciones, la edificación de ermitas, el empadronamiento de los residentes en sus ámbitos y las llamadas de atención a las autoridades sobre algunos remedios para su fomento y conservación, que habrían de obrar a modo de futuros centros de colonización. Jalonado estará su

7 AGI, Mapas y planos, Santo Domingo, 109. Gráfico que representa...los 20 curatos fundados en la jurisdicción de La Habana, 1696.

8 AGI, Santo Domingo, 106. El gobernador de La Habana a S. M., La Habana, 6 de mayo de 1679. El gobernador de la Isla, Francisco Rodríguez de Ledesma, en carta al rey, apuntaba que a Sotavento de la capital vivían 1.500 personas "...generalmente es gente blanca y con familia y que en toda la extensión hasta Cabo Corrientes, se encontraban especialmente ...por toda la costa del sur, que es de muy dilatado circuito", a la vez que en la misma latitud aparecían la mayoría de las estancias, hatos y pesquerías. 
tránsito vueltabajero por fundaciones que se han dado en calificar como parte de una más dilatada "red parroquial". Sobre el carácter de este proyecto de implantación eclesiástica, se ha dicho que: "Si estudiamos detenidamente el trabajo de edificación de parroquias realizado por el obispo Diego Evelino de Compostela puede observarse que el mismo estuvo encaminado a asegurar la presencia de la Iglesia en aquellos lugares donde el desarrollo demográfico y económico tendía a hacer aumentar las riquezas de las mismas (...)". En el caso particular de la Vuelta Abajo, la erección de los curatos de campo respondía a la intención "...de vincular las zonas de cierto desarrollo agrícola, principalmente las vegueras, á la estructura de la Iglesia....". ${ }^{9}$

Naturalmente, hay otros y válidos móviles que explican también este proceso considerando el grado de aislamiento de los pobladores de la región, soslayados de cualquier idea de progreso o mejora en su condición. Como se ha acotado en otro lugar, tal condición les privaba aún "...del consuelo religioso, aglutinante vital de la época..." inclinando a sus dispersos moradores a practicar una existencia "...silvestre y montaraz, casi una segunda especie de indios, tienen una vida muy relajada, viven muy olvidados de Dios y cometen pecados que, por horrorosos, no se pueden nominar...". ${ }^{10}$

Definitivamente, y sin extender la cita en disquisiciones que huelgan, diezmos y prédica nunca estuvieron reñidos en este proyecto, cuyo diseño y consumación honran a sus impulsores, que improntó el devenir social de la Isla, fomentando la colonización de una de las regiones marginales más extensas en tan temprano momento.

9 Torres-Cuevas, Eduardo: Formación de las bases sociales e ideológicas de la Iglesia católico-criolla del siglo XVIII, "Santiago", núm. 48, 1982, págs. 162-163, 165 y ss. En comunicación al Consejo de Indias, el obispo insular, al describir los curatos fundados en 1695 en las regiones del Poniente de la gobernación habanera, mencionaba los de Guanajay, Santa Cruz, San Basilio, Consolación, San Rosendo y Guane. Les calificaba de parroquias “...situadas en los campos sin más vecindad que las a diferentes distancias las circundan...[su condición]...pobrísimas, lejanas y de cortos ingresos, incapaces de mantener el inmueble y subsidiar los gastos elementales del culto y sustento". AGI, Santo Domingo, 2.226. El obispo de Cuba al Real Consejo. La Habana, 9 de noviembre de 1759.

10 Marrero, L.: Cuba: Economía.., tomo 5, cap. 12, págs. 89-91. 


\section{Pedro Agustín Morell}

Pedro Agustín Morell de Santa Cruz y Lora, oriundo de Santiago de los Caballeros, en Santo Domingo, hubo de desempeñar ministerio como provisor y deán de la catedral de Santiago de Cuba, donde ganó prestigio de hábil y enérgico en ocasión de algunos momentos comprometidos de aquella ciudad y su jurisdicción, ya fuese por la revuelta de los esclavos de las minas de Santiago del Prado (1731) o durante la incursión británica a la bahía de Guantánamo (1741). Obispo de Nicaragua en 1749, pasó a similar destino en La Habana, cerca de un lustro después. Intentó, sin éxito, trasladar la sede catedralicia de Santiago a La Habana. Sus diversas visitas de inspección pastoral le llevaron a conocer todo el país “...no dejando poblado ni iglesia en la Isla sin visitar". Por su iniciativa se erigió un colegio de la Compañía de Jesús en Puerto Príncipe y, asimismo, cubrió la fundación del hospital betlemita de Santiago de Cuba, como de escuelas de primeras letras en el pueblo de naturales de San Luis de los Caneyes. Es conocida su posición ante la autoridad británica en la ocupada Habana y que le valió el destierro a San Agustín de la Florida (1762-1763). Implicado personalmente en la reconstrucción de Santiago de Cuba, tras el devastador sismo de 1766, este empeño le granjeó aún más el aprecio de sus contemporáneos. Falleció en la capital de la Isla en 1768, siendo sepultado en la parroquial mayor. ${ }^{11}$

Con toda probabilidad, por las exigencias de su servicio en el Gobierno de Cuba (Santiago y su jurisdicción) nuestro personaje ya había recorrido con cierto detenimiento las regiones más orientales, y este supuesto - junto con su remota localización y lo accidentado de un traslado sin detenida preparación-, puede explicar, a la vez que lo ya reseñado, el interés en agotar, por decirlo de alguna manera, el conocimiento de las jurisdicciones adscritas al Gobierno de La Habana en ambos extremos cardinales, o al menos en aquellos cuyo acceso fuese menos complicado. Tal es así que, optando

11 Santa Iglesia Catedral. Lista de Obispos y Arzobispos de Santiago de Cuba. Museo Eclesiástico. Santiago de Cuba, 1963, págs. 11-13. 
por visitar las localidades comprendidas entre La Habana y Sancti Spiritus, a lo largo de su segundo periplo isleño, entre los finales de 1754 y los primeros meses del siguiente año, recorriera por mar y tierra, arrostrando incomodidades de toda condición, una porción considerable de territorio como las Cuatro Villas, en el centro de la Isla. De vuelta, tras breve alto en San Carlos de Matanzas, y ya en la sede episcopal, registra en sus apuntes que había considerado una corta estancia e inmediatamente proceder en demanda de Sotavento, idea que hubo de desechar ante imperativos que le forzaron a posponerla hasta el próximo verano, con el inconveniente de una estación poco aconsejable para largos desplazamientos por regiones duramente transitables, aun en mejor época del año.

Con todo, lo que no era poco en su contra, el recién investido obispo se decidió por la Vuelta Abajo a comienzos del verano de 1755, según puede leerse en el informe presentado a la Corte, datado en La Habana, a 2 de julio del mismo año, justo al regresar de su primera excursión al Este. Considerando la escabrosidad del terreno, la crecida pluviosidad en época de aguas, las alarmantes distancias, puede dársele el merecido crédito cuando afirmaba que: “...todos admiraron la Vrevedad de mi Regreso porque en Veinte y tres Dias penetre hasta la última Parroquia de las que Caen al Occidente". Con evidente apego al detalle, expone los estimados mínimos y máximos de las distancias recorridas, entre ida y retorno: 128 y 140 leguas terrestres respectivamente. Aún hoy no deja de ser sorprendente la celeridad con que consumó sus deberes. ${ }^{12}$

\section{Su visita a Vuelta Abajo}

Que tengamos noticia, el fragmento de los manuscritos correspondientes a la visita diocesana que nos ocupa, la Vuelta Abajo o parroquias de Sotavento, como eventualmente se les nombra, no ha sido publicado íntegra y textualmente, aunque el resto de sus informes han sido reproducidos, analizados y comentados en varias obras,

12 Una legua provincial cubana era aproximadamente 4'4 kilómetros lineales. 
algunas ya devenidas en referencia. Por otro lado, no dudamos que sea conocida de otros investigadores, como puede deducirse del material depositado en el Archivo General de Indias. Con tales salvedades procedemos a su reproducción. ${ }^{13}$

Nuestro informe o memoria, aparece bajo la denominación genérica de ESPED.TE SRE LA VISITA Q.E HA HECHO Y CONCLUIDO EL OBISPO DE AQUELLA YSLA EL FR. PEDRO AGUSTIN MOREL DE STA CRUZ; AÑO DE 1759., en la sección quinta, correspondiente a la Audiencia de Santo Domingo, legajo 543, en el monumental depósito sevillano. Por la correspondencia adjunta, se conoce que la relación fue remitida a la Corte en Octubre de 1758, especificándose que la serie de visitas realizadas a lo largo de la Isla de Cuba se inició en el 1754, apenas llegado de Campeche, concluyéndolas en 1757. Según registro del Consejo de Indias, los informes fueron enviados en sucesivas partidas, en forma de “...otras relaciones... separadas conforme la iba executan-

13 El obispo Morell no sólo ha trascendido por el ejercicio de su dignidad sino también como cultor de la historia, donde logró reputación por obras como su Historia de la Isla y Catedral de Cuba (La Habana, 1928) entre otras. Su abultado informe o relación eclesiástica, de la cual existen dos originales en el Archivo General de Indias - la una, que se conserva íntegra en el fondo Audiencia de Santo Domingo, 534; la otra parcial, en Indiferente General, 190-A - ha sido revisado minuciosamente por autores como el profesor Leví Marrero en su serie Cuba: Economía y Sociedad, Madrid, 1972-1980, especialmente en el volumen 6, capítulo I, páginas 66-70, donde muestra un resumen geoeconómico de los asentamientos insulares entre 1754-1757, entre ellos los de la Vuelta Abajo, aunque sin reproducción total del contenido. Por su lado, el investigador César García del Pino, en La visita eclesiástica (La Habana, 1986), ha trabajado la figura del prelado-viajero y publicado textualmente las relaciones de los periplos, excepto el de Sotavento, partiendo también de fuentes documentales. En un artículo titulado: La configuración del espacio colonial en Cuba ("Revista de la Biblioteca Nacional José Martî". La Habana, enero-agosto 1982, volumen XXIV, 1-2, págs. 63-95), la investigadora Carmen Gavira ha reproducido datos provenientes de los informes de las visitas al interior de la Isla, a partir de las fuentes primarias. Recientemente, hemos visto en la sección "América en el siglo XVIII" de la Historia General de España y América, (Madrid, 1989, tomo XI, volumen 2, 3. ${ }^{\text {a }}$ parte, página 548 y siguientes) el empleo de la información cuantitativa de los originales conservados en la papelería cubana del AGI. Todas estas referencias tienen en común el haber derivado sus datos de los citados legajos del archivo sevillano, lo cual es también nuestro caso. Por último, vale acotar que ya en el pasado siglo la información episcopal había sido materia de consulta, tal como comenta Antonio J. Valdés en su Historia de la Isla de Cuba y en especial de La Habana. La Habana, 1964, libro IV, pág. 91. La edición príncipe data de 1813. 
do de las quales tienen ya copias todos los Sres. Camaristas...". ${ }^{14}$ La más completa serie de la visita se dispuso quedara en la Secretaría del Consejo "...por ser muy bolumosa..." (sic) según nota y extracto de la carta hechos en el citado Consejo, a donde habían sido remitidas por el secretario de Marina e Indias, Julián de Arriaga, cumplimentando real deseo, con intención de que el citado concilio “...haga de ella el uso conveniente: y si contuviere alguna noticia $o$ materia sobre que considerase precise providencia de S.M. consulte lo que se ofreciere y pareciere". ${ }^{15}$

A despecho de las varias observaciones del obispo acerca de la necesidad de mejoras en el país, propuestas para el fomento de la población, los caminos o la educación entre otros tópicos que subraya a lo largo del memorial, y más allá del caso que nos ocupa, el fiscal del Consejo de Indias, en su respuesta a Arriaga, dada en febrero del mismo año, opinaba que en lo que a contenidos atañía, y según unánime criterio "...le pareze no ay que hacer cosa alguna sre el particular....". ${ }^{16}$

Así, la seca prosa de un funcionario, junto con la escasa inclinación de los ministros a distraer sus personas de "graves asuntos de estado", condenaba un cuatrienio de esfuerzos, arduos desplazamientos, constantes y puntuales informes, amén de buena copia de lúcidas apreciaciones, al forzado ostracismo de un legajo que vendría - paradoja común - a rendir cometido dos siglos más tarde, ante la tardía inquisición de los investigadores.

14 AGI, Santo Domingo, 534. Dictamen del Consejo de Indias, Madrid, 1759.

15 Ibídem. Julián de Arriaga al Consejo de Indias, 9 de enero de 1759.

16 Ibídem. El Consejo de Indias, Madrid, 9 de may• de 1759. 


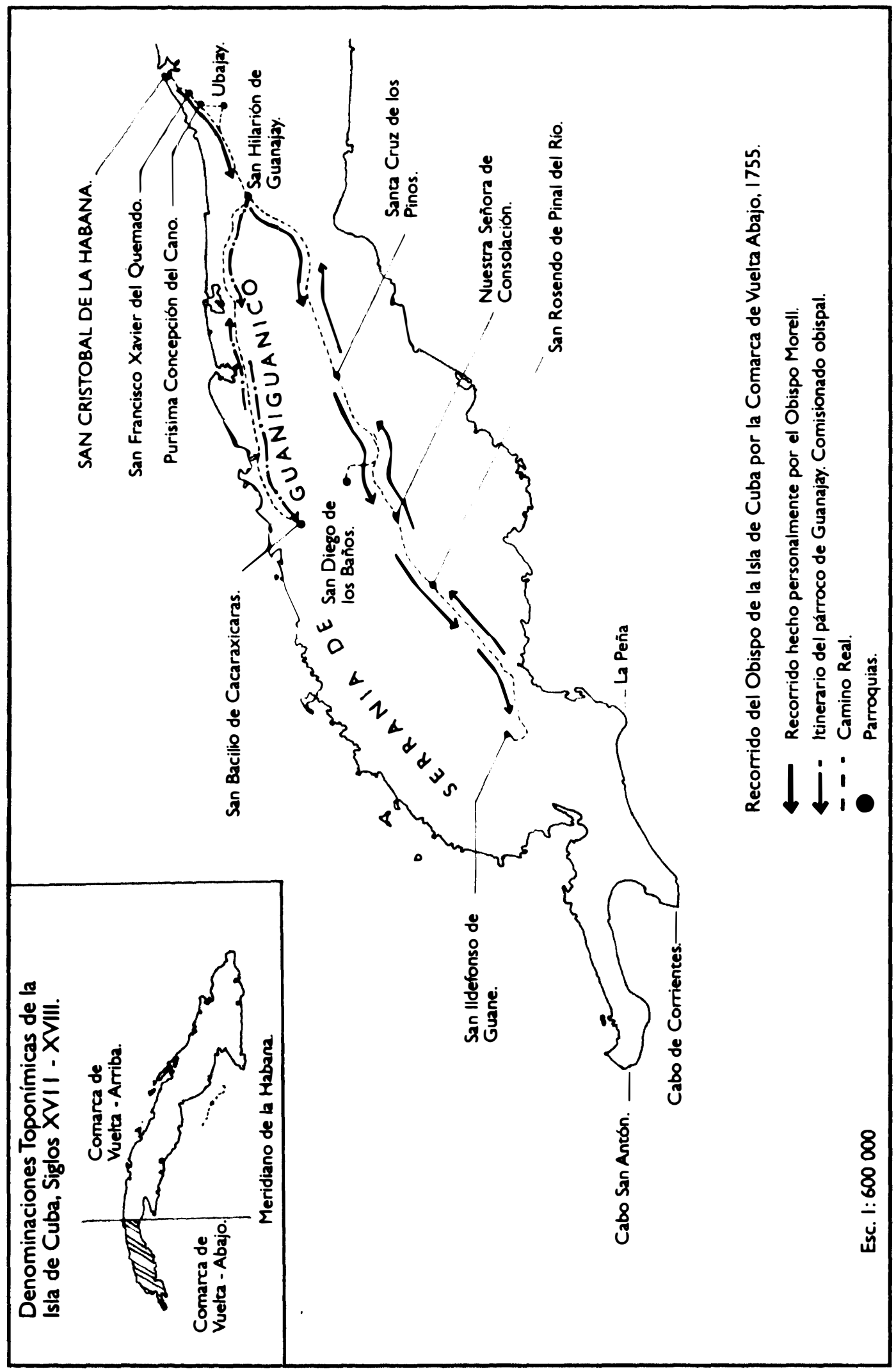

Anuario de Estudios Americanos 


\title{
Apéndice
}

\author{
ESPED.TE SRE LA VISITA Q.E HA HECHO Y CONCLUIDO \\ EL OBISPO DE AQUELLA YSLA EN FR.DN PEDRO AGUSTIN \\ MOREL DE SANTA CRUZ; AÑO DE $1759^{17}$
}

\section{“Señor:}

164. Quemados. (...)Deseoso de Evaquar este cuidado emprehendi mi Marcha y arrive a la Yglesia del Partido de los Quemados. Dasele este Nombre porq.e antes era un monte firme y espesso para reducirlo á la campaña fue preciso valerse del fuego y quemarlo Termino usual para declarar estas maniobras es Auxiliar de las Parroquiales de esta Capital cae al óste de ella a distancia de tres leguas. Antes hubo ótra mas abanzada un quarto de legua acia la misma ciudad mi Antessesor la hizo derrivar y construyo sus Expensas la áctual vajo el titulo de Nra. Señora de la Charidad y Sn.Fran.co Xavier consta de un Cañon con su cruzero de mamposteria y teja corre de Norte á Sur Tiene Tres Puertas de Longitud quarenta varas Doze de Latitud, y diez de Altitud con Siete Altares Su Baptisterio de Piedra, Pulpito, coro alto, y Organo todo nuevo y decente a las Espaldas - Cae la Sacristia Su largo dose Varas seis de ancho y alto Sobre ella queda una Sala y apocento para el Teniente de Cura y un Sachristan menor. Las campanas que son tres quedan en otro tantos Arcos a la Frente. El territorio de la administración comprehende dos Leguas de Largo y una y tres quartos de Ancho hallase diez y seis Casas de Paja con inmediación a la Yglesia aunque sin Orden y cincuenta y seis repartidas por los campos ciento y ónze Estancias cinco Ingenios nueve Molinos de Tabaco y dos hornos de cal, y ciento óchenta y tres familias con un mil quatrocientos sesenta y dos personas. Hay también Tres compañías de Montados compuestas del Vecindario con sus Capitanes y Respectivos oficiales pero ningun Juez para lo político —en lo que se ófrece es preciso acudir a la ciudad, lo mismo Succede pr. lo tocante a lo Ecleciastico á distanc.a de tres quartos de Legua ácia al Norueste queda una fortalezita Nombrada Maria Nabo con ocho soldados que sirven de Vigía. Dos Dias me mantu-

17 Ibídem. Correspondiente al año 1755, págs. 158-170, según foliación antigua, folios $165-178$, serie actual. 
ve en esta Yglesia la vicité y reglé en todo lo que necesitó prediqué dos sermon.s y confirmé ciento y veinte y ocho personas dejé p.r fin encargada la devoción del Santíss.mo Rossario.

En el diez y nueve continue mi marcha al Sudueste passadas dos Leguas cortas llegué a la Yglesia del Cano su titular la Purisima Concep.on en lo ántiguo se reducia a una Hermita de paja, ávra veinte y ocho años que se Arruinó y Dn. Francisco del Barco Medico de esta ciu.d levantó ótra en su Lugar desde entonces se erigío por Auxiliar de Guanajay. Consta de un Cañon de mampostería y teja corre de Norte á Sur Su longit.d Veinte y ocho varas su altitud y Latitud Diez. En ella hay quatro Altares y Pulpitos con moderada Compostura, y so coro alto aunq.e sin Organo la Sachristía queda a las Espaldas con Diez Varas de largo y seis y una quarta de áncho y alto, sin Adorno, y todos hornamentos indecentes. Sobre ella un quarto que Sirve para havitación del Sachristan encima de la Puerta pral. Dos campanas sobre ótros tantos Arcos de Ladrillos tiene su osario de Cal y Piedra a la Parte del Leste sercanla diez y nueve cassas de Paja otras Siete quedan en el Termino de su administracion. Esta se extiende á quatro Leguas de Longitud y una y tres quartos de Latitud. hay en ellas Doscientas setenta y nueve Estancias, y un Cacagual con casas tambien de paja. Veinte ingenios Sus fábricas son de Piedra y teja y las havitaciones de los Negros de la misma paja que llaman Bohios llegan á veces á quarenta, Nueve texares, y una Hermita de cal y Piedra Nombrada la Pastora de Sn Luis Guatao. Trescientas y diez familias con dos mil setecientas treinta y dos personas, y finalmente Tres Compañias de Montados de los Vecinos con sus Capitanes y respectivos ofiziales por lo qe. se ofrece en lo Politico se ocurre al Gov.or de esta Ciudad y para lo Ecc.o al Obpo. ó Provisor. Mantubeme en esta Yglesia los mismos dias y practiqué enteramente las proprias funciones q.e en el Quemado confirmé trescientas personas.

167. Guanajay. Siete Leguas en Demanda del Norueste demora la Parroquia de Guanajay su Titular Sn. Hilarión la Puerta pral. queda al Oriente, y otras dos a los Costados. Consta de un Cañon con techo de teja sobre horcones forrados de Tablas. Su Longitud veinte varas su Latitud ócho y su altitud cinco hay dos Altares mui pobrem.te Vestidos en el m.[ayo]r sirven quatro candeleros de palo mui Viejos y Sucios. La cruz Parroquial, y los Ciriales son de madera plateada. Tiene también su Pulpito de lo mismo pintado. La unica Alhaja áprectable [sic] se reduce á una Lampara pequeña de plata á Espaldas esta la Sachristía con ocho Varas de Largo cinco de alto y ancho Sin Adorno ni ornam.tos decentes sobre ella cae una pieza de los mismos Tamaños para la havitación del Cura en la Solera de un Corredorcito por donde se entra queda una Campana me- 
diana sin sostenido porque esta quebrada en efecto nada de estim.n hay en esta Ygl.a.

Fabricose el año de Treinta y cinco en lugar de ótra que havia de paja y fue la primitiva erigida por el R.do Obispo Evelino en veinte y cinco de Mayo de el Noventa y cinco del Siglo passado el termino de su administracion excluso el de la Auxiliar de el Cano comprehende Catorze Leguas de Longitud y seis de Latitud. La Bahía del Mariel se incluye en ella. Tiene siete Soldados con su Cabo en un Morrillo. Sirven de Vigía y de dar áviso á esta Capital de las embarcaciones que trancitan. Un Yngenio, treinta y dos hatos y corrales, y ótras tantas familias compuestas de Doscientas Sesenta y ocho personas. Dos dias me mantube en este citio á donde Llegué el Vein.te y uno confirmé diez personas y no hize mas función por defecto de concurso el q.e hubo se redujo a diez personas havitantes en una cassa de paja del mismo citio. La Yglesia queda dentro de sus Sercas y por este motibo ni hay Vecindario ni ásisten á la Parroquia. El cura anda por las haciendas para Exercer Su Ministerio. Celebra el Santo Sacrificio de la Missa, Baptismos y Matrimonios óye Confeciones y da la Comunion en los Bohios indecentes de las mismas haziendas estas funciones son comunes á todos los Curas del Monte las Yglesias también carecen de Renta para su Manutencion. La pral: qe. es el noveno y medio de los Diezmos la percive y consume el mayordomo de las Parroquias de esta Ciudad sin mas pención que Diez pessos q.e contribuye ánnualm.te para pan, vino y sera, y los hornamentos Desechados que manda para el servicio de ellas. Es precisso pues q.e se hallen faltas de un todo según tengo representado á V.M. en consulta de nueve del mes de noviembre del año proximo passado Lo que practiqué assi en esta como en las otras Parroquiales fue mandar al referido Mayordomo las proveyese de lo por ahora necesitavan.

[Los Pinos] Caminadas quince Leguas, Llegué día Veinte y quatro a la Parroquial del Partido de los Pinos, queda al óeste de la de Guanajay corre de Norte á Sur. Consta de solo un Cañon de Horcones y madera toscamente labrada.techo de teja. Su Longitud diez y seis Varas Su Latitud siete y su altitud cinco Yncluye un Pulpito de Madera y dos Altares -mui pobres una Lampara de plata pequeña áunque no hay Sacram.to ni Sagrario la cruz es de. palo plateado, y los candeleros quatro dos de ellos grandes de madera enyesados, y los ótros dos pequeños de estaño tiene $\mathrm{Su}$ pila Baptismal, y algunos Hornamentos de media Oida á Espaldas esta la Sachristia con siete Varas de largo, quatro y media de ancho y de alto tres sobre ella un quarto que Sirve p.a la havitación del Ministro pral. que es el Cura ácompañale otro con Titulo de Sachristan m.r pero sin mas renta q.e ciento y cincuenta pessos por Razon de Teniente del mismo Cura, hay 
dos campanas pequeñas pendientes de quatro horcones, todo lo referido se fabricó el año de Treinta y cinco y se derribó la Yglesia antigua que era de paja hallavase Cituada dos Leguas mas distante en la hazienda nombrada Santa Cruz hizose su Erección el año de Seiscientos Noventa y cinco por el Rdo. Obpo. Evelino. El termino de la administración se extiende a seis Leguas de Latitud sobre treze de Longitud Numeranse cincuenta y cinco haziendas de Ganado m.r y menor una de ellas con hermita de paja donde confirmé cinco personas, Siete Vegas, y tres Thenerias Sesenta y cinco familias Trescientas cincuenta personas adultas y cincuenta parbulos. inmediato a la Yg.a se hallan cinco cassas con sus óficinas, y otras tres como á distancia de dos quadras todas de paja-Hay finalmente en este citio una compañia de los Vecinos montados con su Capitan y respectivo ofiz.s. En esta Parroquia me mantuve un dia confirme diez personas y por defecto de concurso deje de Predicar y concluy mi Vicita.

169. Consolacion Catorze Leguas al Sudueste se halla un hato nombrado Nra. Señora de Consolación. El Rev.do Obispo Evelino erigio en el por el año de Seiscientos y Noventa una Parroquia vajo de el Titulo de la misma Señora cituose dentro de las Sercas del referido Hato esta sircunstancia servia de grave perturbacion al Cura para la celebracion de los Divinos oficios. Ocurriase Sobre el Asumpto a mi Antescessor quien Ynformado ócularmente de la verdad de el hecho en la Vicita q.e hizo el año de Setecientos Treinta y quatro Determino se construyese ótra á distancia de seis quadras de la primera perfeccionose en el Siguiente de Treinta y Cinco, y desde entonces se ábandono la antigua q.e era mui pequeña y se mudó la administracion a la nueva. Corre de Leste á Oeste consta de un Cañon de madera y paja su Longitud diez y nueve y media varas Su Latitud ócho, y cinco y quarta su altitud contiene Tres Altares mui decentes el resto de el esta algo desgraciado por las goteras que a padecido. Lampara, cruz, Incensario, Naveta y Caldereta todo de plata. Su Baptisterio de piedra, coro alto, Pulpito de madera Doze candeleros de lo mismo plateados dos de Estaño, a Espaldas cae la Sacristia con ocho varas de largo cinco y dos quartas de ancho y tres de alto algunos de sus hornam.tos nuevos y ótros usados sobre ella esta un quarto para la havitaz.on del Ministro tiene dos Campanas pequeñas en tres palos Siete cassas de paja embarradas con inmediacion El termino de su Jurisdiccion se extiende á Veinte Leguas de Longitud y quinze de Latitud ay en ellas Sesenta y una haziendas de Ganado m.r y menor y noventa y una vegas, ciento y quarenta y dos familias y setecientas y cincuenta y tres personas de todas edades. Dos compañias con sus capitanes y respectivos óficiales y un Juez de Comicion para los Juicios Verbales en lo civil pero en lo criminal solo 
previene y da cuenta al Governador de esta Ciudad q.e es quien lo nombra. En este partido hay tambien un Rio titulado Sn. Diego que tiene tres Especies de baños unos frios otros templados, y otros calidos de Azufre mui saludables Segun las Enfermedades de los q.e acuden a ellos q.e son en gran numero Un Cura exerce la Jurisdicc.on Ecc.ca como Vicario foraneo no solo de su Partido sino tambien de los de Santa Cruz, Pinal del Rio, Cacaraxicaras, Guane, y Guanajay.

170. Funciones y Providencias. Dia Veinte y seis Llegue a la misma Yglesia mantubeme en ella un dia predique un sermon confirme Veinte, y ocho personas y anteriormente, otras doze en el discurso de mi Marcha, di Providencia para q.e el Mayordomo de fabricas de las Parroquiales de esta Ciudad remitiesse con brebedad entre ótras cosas un Relicario de plata para llevar el Viático a los enfermos y un Copon para ministrar la Comunion y ultimamente procure exforzar los ánimos de los havitantes a la construccion de otra Yglesia mas capaz de Piedra y Teja y que se estableciessen sobre su lugar para la mas commoda administracion de los Sacram.tos y Salvacion de sus Almas prometiendoles de mi parte interesarme en facilitarles los medios para su Consecucion.

171. Pinal del Rio y sus Ygles.s Quatro Leguas al óste de el Curato de Consolación comiensa el de Pinal del Rio que es el nombre del Hato en que se halla situado extiéndese á Veinte Leguas de Longitud y ónze de Latitud. En ellas hay Quarenta Haciendas de Ganado m.r y menor, y óchenta Vegas setenta y seis familias y seiscientas y quarenta personas de todas edades y ultimamente una Compañia de montados Compuesta de los mismos Vecinos con su Capitan y respectivos óficiales ha tenido Tres Yglecia. La primera erigida por el Rdo. Obpo. Evelino el año de Noventa y nueve del siglo passado, en el áciento viexo de el mencionado Hato este y áquella se mudaron por las inundaciones de el Rio en que se hallavan con inmediación. La seg.da se consumó en quinze de Noviembre de Setecientos Veinte y Seis permanece hasta el precente en el aciento nuevo bajo de sus sercas. Abandonose tambien por la grande humedad del terreno, y la Terzera se halla á distancia de media Legua, y se principio el año de quar.ta y nueve todas han merecido un mismo Patron y Titular que es San Rozendo.

172. Estado de la Segunda Con el motibo de haver mencionado el dia Veinte y ocho en el Referido Hato reconocí la Segunda y hallé que además de ser mui pequeña de tablas y paja estaba inservible, pendiente mi Demora confirmé ócho personas Vicité los Libros Parroquiales y vi los hornamentos que sobre pocos son indecentes. 
173. el de la Terraza Dia veinte y nueve trancité por el paraje en q.e existe la Tercera. Corre de óeste á Leste consta de un Cañon con Trece Varas de largo cinco de áncho y tres de álto Su Techo es de paja Sobre horcones y sin Serca alguna ni altar celebrase el Santo Sacrificio de la missa en la sala de un Bohio en que havita el Cura. Este tiene guardada una Lampara, Cruz, y quatro Blandones todo de plata perteneciente a la misma Yglesia y Tres campanas me expressó q.e su animo era hazerla más capaz de Mampostéria y Teja, y servirse en el interior de la ótra. No me parece Surtirá efecto por que ni el ni sus feligreses, ni la Yglesia tienen caudal álguno para la empressa encargele en fin solicitasse perfeccionar la Yniciada del modo que pudiera.

174. Guane. El Ultimo curato q.e cae al óccidente de esta Capital es el de Guane dista de ella sesenta y quatro leguas. Erigiólo el Rdo. Obpo. Evelino en el año de Noventa y quatro del Siglo passado vajo del titulo de San Yldephonso Su Parroquial es de madera y paja corre de Sur á Norte con doce Varas de Longitud, seis y media de Latitud, y tres y quarta de Altitud incluye dos Altares mui pobres Pulpito y Baptisterio. No tiene Sagrario. La Sacristía cae a las espaldas. Su largo seis y media varas Tres de áncho y Tres y quarta de álto sin ádorno, los ornamentos Son pocos e indecentes. La cruz Parroquial de palo plateada, y una campana pequeña pendiente de dos palos q.e Sirven de Campanario el termino de la administración se extiende á quarenta Leguas de largo las Veinte de ellas inhavitables que terminan en el Cabo de San Anton y doce de ancho en el Paraje que Llaman la peña-distante diez leguas al oéste de $\mathrm{Ca}$ bo San Anton hay una Vigia de Siete Soldados y su cabo puesta p.r el Governador de esta Ciudad para dar aviso de las embarcaciones q.e Trancitan por ella. Comprehende tambien Cinquenta y siete haciendas de ganado m.r y menor, quarenta y una Vegas, Noventa y ocho familias y Setecientas personas de Todas Edades en el Contorno de la Parroquia solo hay Cinco casas con sus oficinas, y dos Compañias compuestas de los Vecinos montados con Sus Capitanes y Respectibos Ofiz.s. Un dia me mantube en ella confirmé doce personas y Treinta y dos en el discurso de mi marcha q.e duró dos dias. Concluí en fin mi Vicita dando providencia sobre el remedio de las necessidades que toque.

175. Regreso y funciones executadas en el Dia dos de Mayo sali de Guane en Demanda de esta Ciud.d por el mismo Camino q.e havia emprendido mi marcha en el discurso de ella confirmé ciento y quatro personas, Coloqué a la Magestad Sacramentada en la Parroquial de Consolación Prediqué en ella Segunda Vez Provey auto para averiguar la 
distancia de cada Curato de los cinco por donde havia trancitado. el numero de sus haziendas y vegas familias y personas de q.e se componen las dificultades que se ofrecen para la administración de los Sacramentos la indecencia con que se executa y las demas que me parecio conveniente para hazer constar judicialmente lo mismo que havía tocado en mi Vicita y con vista de ello procurar el Remedio de las Necessidades Espirituales de aquellos infelizes que viven en las Tinieblas de la ignorancia y expuestos á perderse para Siempre.

176. Llega a esta Capital comete a un Preb.o la Vicita de Cacaraxicaras Llegue p.r fin á esta Capital en el onze del mismo mez Todos admiraron la Vrevedad de mi Regresso porque en Veinte y Tres Dias penetré hasta la última Parroquia de los que Caen al Occidente. El menor computo de un Viaje redondo hasta el mencionado termino se reduce á ciento y Veinte y ócho leg.s y el m.r a ciento y quarenta. Evaquelas en diez dias Utiles los demas Se consumieron ó en mancionar [sic] sobre los Lugares ó para el descanso y exercicio del Ministerio, ó para evitar el mal tiempo de las águas que Sobre vinieron faltome Sin embargo un Curato que Visitar Situado en la Costa del Norte Llamase Cacaraxicaras ponderandome mucho lo intraficable de sus caminos y lo peligrosso de sus Zerranias son tan elevadas que por algunos dias las haviste desde el camino Real á distancia de diez Leguas no me faltó el ánimo para penetrar el paraje en q.e se halla la Parroquia-decistí unicamente del intento por las muchas dificultades que los conductores me propucieron. Resolví en fin cometer la Diligencia a Dn. Patricio Rodriguez Aldado Teniente de Cura de Guanajay encomendándole al mismo tiempo la áveriguación g.e llevo relacionada que las evaquasse con brebedad y me la remitisse." ${ }^{8}$

(...)

"187. Cacaraxicaras La remitida por el de Cacaraxicaras distante Treinta Leguas al oéste de esta Capital se reduce a la Siguiente la Ygl.a consta de nueve varas y quarta. de Largo quatro y tres quartas de áncho y dos Varas de alto con Techo maltratado de paja y paredes de Tablas encierra dos Altares en el m.r hay una Varanda de Zedro q.e lo encierra. Un

18 En el folio antiguo 170 ( 178 actual) anota que pasa a enumerar ciertos curatos del lado oriental que encomendó al doctor Gallo, y que personalmente no consiguió alcanzar en ocasión de su visita "...por la precisión de mi marcha..." siendo los nominados Copey, Varajagua, Albares, Guamutas, Guamacaro, Río Blanco, Hanavana, Macuriges, Guines y Palma o Ciego de Avila. En el folio 180, 188 actual, menciona los datos conseguidos por su comisionado en Sotavento, quien los compiló en su nombre por la misma razón. 
quadro grande de Sn. Bacilio q.e es el Titular y ótras Laminas de diferentes advocaciones el otro Altar de las Animas mui derrotado tiene sola una puerta con dos campanas pero no Sacristia todo en fin lo que se rexistra en esta Yglesia son indecencias y Pobressa esta Junto con la áspereza de los Caminos es causa de q. con dificultad se encuentre Minro. que la Sirva el termino de esta se extiende a diez y nueve Leguas de Longitud y siete de Latitud en ellas existen Treinta y Tres Haziendas de ganado m.r y menor ótras tantas familias doscientas treinta y ocho personas."

\section{(...)}

"Nro. Señor Guarde la C.R.P. de V.M. como la Christiandad ha menester y sus Vasallos Necesitamos. Havana y Julio 2 de 1755.-Pedro Agustin Obpo. de Cuba. (Rúbrica)." 